\title{
Report of the investigation of the flood disaster that occurred on May 5, 2012 along the Seti River in Nepal
}

\author{
Hidetomi OI ${ }^{1}$, Daisuke HIGAKI ${ }^{2}$, Hiroshi YAGI $^{3}$, Nobuhiro USUKI ${ }^{4}$, Kousuke YOSHINO ${ }^{4}$ \\ 1 International Sabo Association (2-7-5 Hirakawa-cho, Chiyoda-ku, Tokyo 1020093, Japan) \\ 2 Faculty of Agriculture and Life Science, Hirosaki University (3 Bunkyo-cho, Hirosaki, Aomori 0368561, Japan) \\ 3 Faculty of Education, Art and Science, Yamagata University (1-4-12 Kojirakawa-machi, Yamagata, Yamagata 9908560, Japan) \\ 4 Asia Air Survey Co., Ltd. (1-2-2 Manpukuji, Asao-ku, Kawasaki, Kanagawa 2150004, Japan) \\ E-mail: usu.usuki@ajiko.co.jp
}

\begin{abstract}
On May 5, 2012, a rockslide occurred on the western cliff of Annapurna IV and triggered floods, which ran down the Seti River causing serious damage to villages and tourist spots along the river. Considering the seriousness of the disaster and the necessity of investigating the phenomenon for disaster mitigation in Nepal in the future, the NPO Nepal-Japan Friendship Association for Water-induced Disaster Prevention (NFAD) dispatched a survey team 1 month after the disaster, which remained on site from June 2 to 10, 2012. The survey was carried out smoothly and satisfactorily owing to the kind cooperation of the Department of Water-Induced Disaster Prevention (DWIDP), The International Centre for Integrated Mountain Development (ICIMOD) and others. Good weather, despite the rainy season, and the carefully arranged logistical support were also key factors in the success. A helicopter survey focused on the western flank of Annapurna IV where the rock slides and rock avalanches that triggered the disaster occurred. Soil materials were collected and compared with the deposits in the downstream areas. Reconnaissance along the Seti River confirmed a “dam up” at Kapuche and severe bank erosions at various places along the river. The deposits along the river were confirmed to be identical to the materials collected during the helicopter survey. Interviews at affected villages, district offices, schools etc., were useful for understanding the actual situation at the time of the disaster. All interviewees responded to our abrupt questions without prior notice with various pieces of information. We are certain that progress has been made in research on the mechanism of rock slides/rock avalanches/mudflows, using practical approaches such as helicopter surveys, reconnaissance surveys, and interviews. We hope that this report will further advance research to mitigate the effects of this type of disaster in Nepal in the future.
\end{abstract}

Keywords; Nepal, Seti River, rockslide, dam up, mudflow

\section{INTRODUCTION}

On May 5, 2012, a rockslide occurred on the western wall of Annapurna peak IV, which is located at the source of the Seti River in the Gandaki River system in north-central Nepal. This rockslide caused a large-scale flood that resulted in serious damage to settlements and tourist spots along the river. Immediately following the disaster, photographs of the dust generated by the rockslide, floods, and damage were taken by pilots on sightseeing flights, residents, and so forth, and were distributed on television, in newspapers, and on the Internet. These media suggested that a glacial lake collapse was the cause of the disaster, as the weather was fine when the disaster occurred.

It is vital to investigate the actual conditions and elucidate the mechanism of this disaster, as Nepal has measures against sediment disasters specific to the Himalayas, such as glacial lake outburst floods (GLOFs). Therefore, the Nepal-Japan Friendship Association for Water-induced Disaster Prevention (NFAD) implemented aerial investigations using a helicopter, field investigations, and a hearing involving disaster victims along the Seti River from June 3 to 8, 2012. This report summarizes the results of this investigation and provides an assessment of the current view of the cause of the disaster.

\section{OVERVIEW OF THE DISASTER}

\subsection{Overview of the damages}

Fig. 1 shows the location and a profile drawing of the Seti River, obtained from the Shuttle Radar Topography Mission (SRTM). As a result of the 

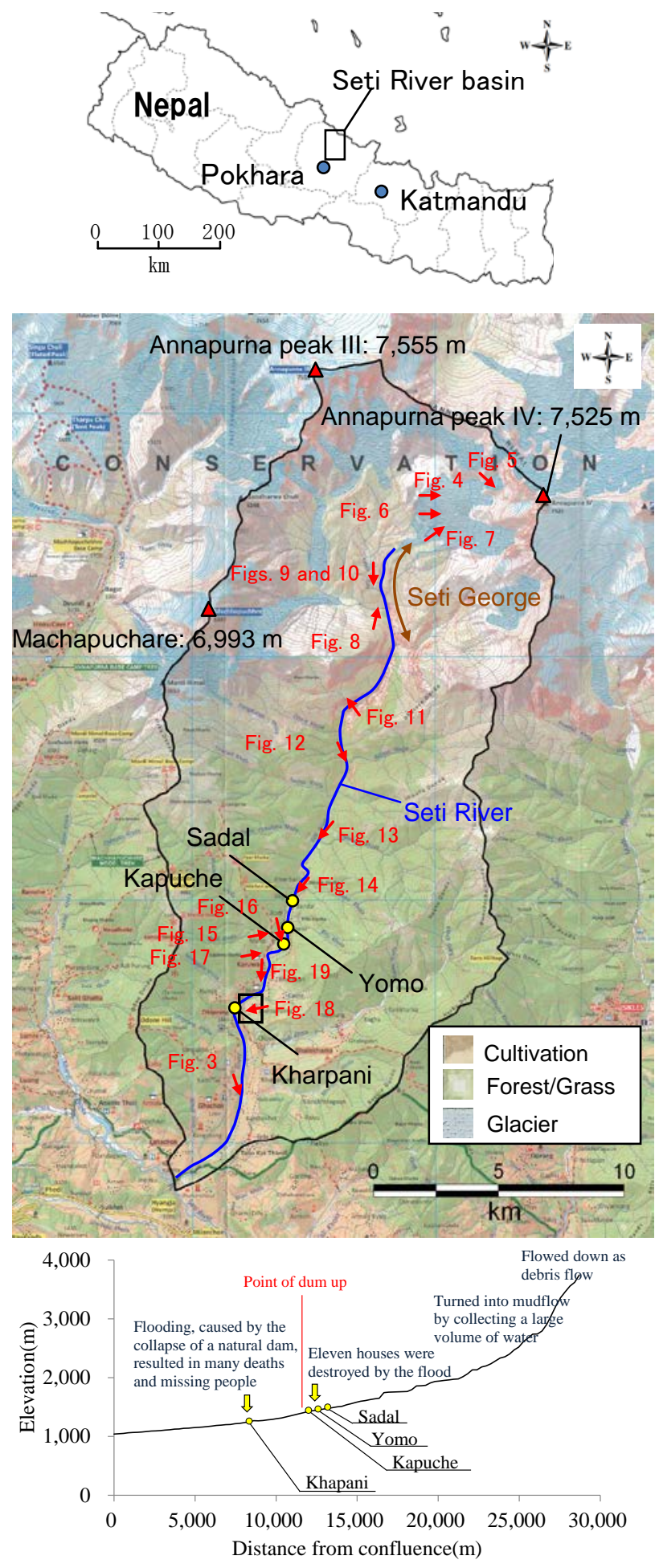

Fig. 1 Location and profile drawing of the Seti River

rockslide on Annapurna peak IV and resulting floods, over 70 deaths and missing persons were reported in the Seti River basin, with most of the victims concentrated around the Kharpani region. Fig. 2 shows images of the Kharpani region before and after the disaster.

In Fig. 2, the photograph on the left was taken immediately before the flood reached the Kharpani region. It can be seen in the after photograph on the

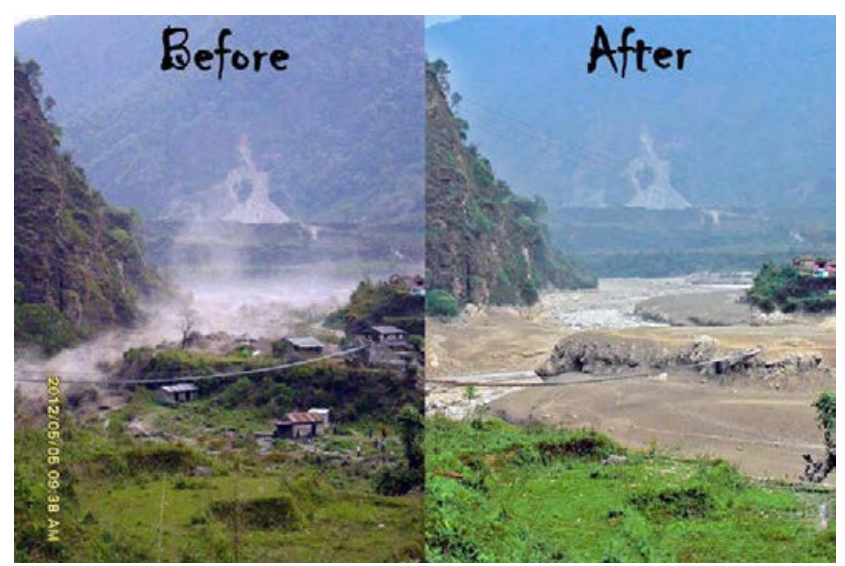

Fig. 2 Conditions of the Kharpani region before and after the disaster [Dahal et al., 2012]

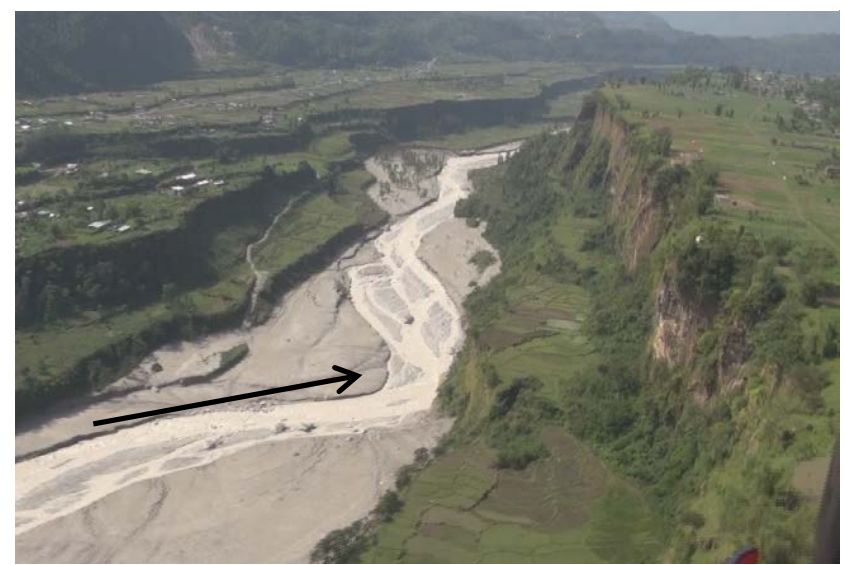

Fig. 3 Terrace in the Seti River downstream basin (taken at 09:21, June 4, 2012)

right in Fig. 2 that the flood rose to above the terrace, which was approximately $12 \mathrm{~m}$ in height relative to the riverbed, and that all of the houses were washed away. This region was a tourist spot due to the hot springs originating from the Main Central Thrust (MCT). Tourists who were using the hot springs were victims of the disaster as it occurred on Saturday, May 5, 2012, a holiday in Nepal. In addition, the flood washed away 11 of the 13 residential houses in the Yomo region, which is $\sim 4 \mathrm{~km}$ upstream of the Kharpani region; the remaining two houses sustained severe damage and are now abandoned. As all of the disaster-struck areas were filled with muddy sediment, it is assumed that a large amount of sediment was transported from the upstream area.

\subsection{Overview of the basin}

Machapuchare (6,993 m), Annapurna peak III (7,555 m), and Annapurna peak IV (7,525 m) are the sources of the Seti River, and large terraces have formed along the river (Fig. 3). This basin has supplied a considerable amount of sediment for a long time and formed the Pokhara plateau downstream. 


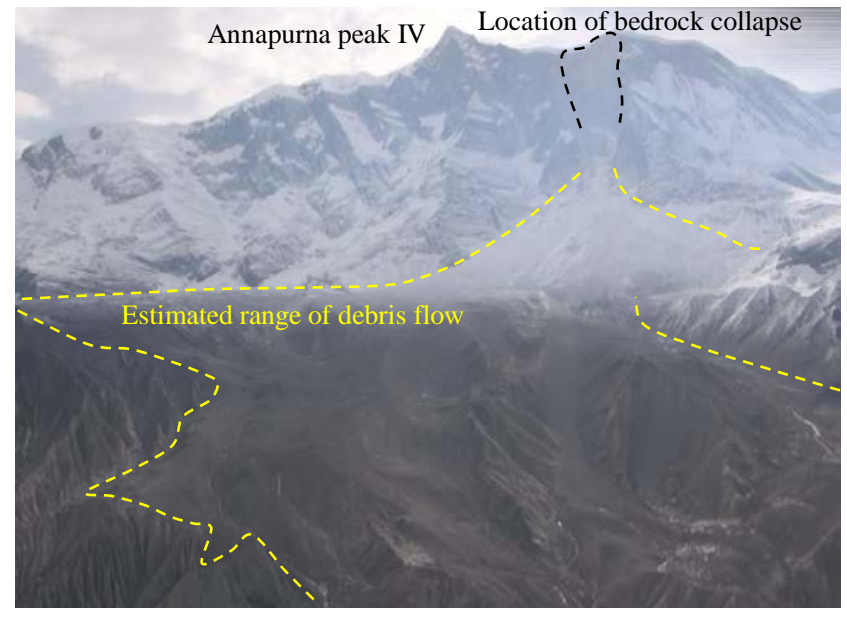

Fig. 4 Complete view of bedrock collapse on the western wall of Annapurna peak IV (flat surfaces can be seen at the center of the photograph)

The upstream region surrounded by Machapuchare, Annapurna peak III, and Annapurna peak IV has a wide distribution of calcareous sediment, with glacial deposits and lacustrine sediments forming alternating strata. The word "seti" means "white" in Nepali, and the water in the Seti River usually has a milky white color due to the dissolved calcareous sediment that originated from the upstream area.

\section{CONDITIONS OF THE ROCKSLIDE, DEBRIS FLOW, AND MUDFLOW EVENTS}

\subsection{Conditions of the rockslide}

The estimated scale of the rockslide that occurred on the western slope of Annapurna IV (Figs. 4 and 5) was $850 \mathrm{~m}$ in height, $550 \mathrm{~m}$ in width, and $70 \mathrm{~m}$ in thickness, which is a volume of approximately $32,725,000 \mathrm{~m} 3$, based on the Landsat7 satellite images taken on April 20, 2012 (before the disaster), and on May 6, 2012 (after the disaster). The bedrock became pulverized as it collapsed, scattering over the glacier and flowing down over the former glacial deposits distributed below the glacier as debris flow (Fig. 6). The gutter-shaped flow channels that formed during the disaster are also visible.

As shown in Fig. 7, the former glacial deposits formed as pointed, needle-shaped earth pillars due to erosion. However, the shape of the glacial deposits changed into a slightly rounded ridge in areas where the debris flowed downhill, indicating that the debris flow moved downward while eroding the former glacial deposits. The limestone stratum below the former glacial deposits had previously formed the deep Seti Gorge (Fig. 8) through erosion by rainwater and meltwater. Because traces of mudflow can be seen around the gorge, it is

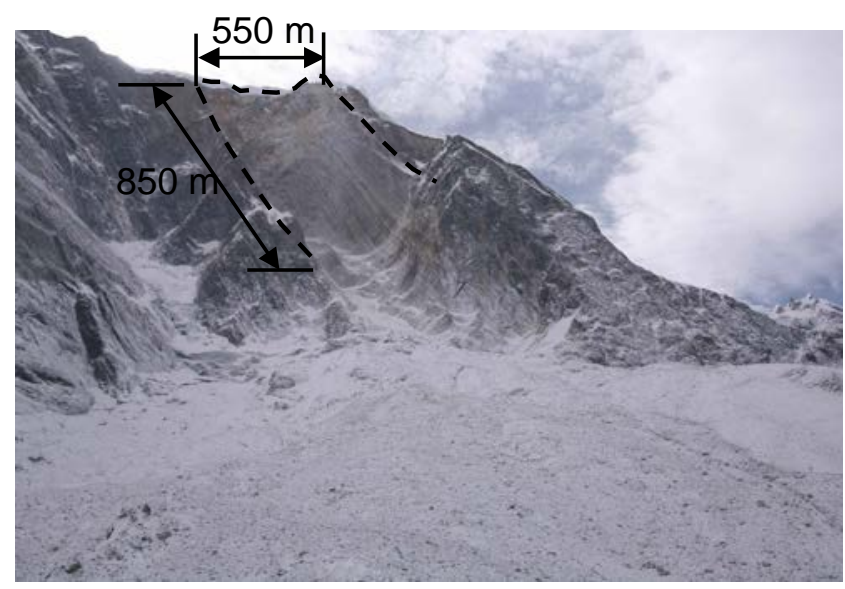

Fig. 5 Bedrock collapse on the western wall of Annapurna peak IV (the center of the screen is the site of the bedrock collapse, and pulverized pieces of rock can be seen on the gently sloped surfaces at the foot of the peak)

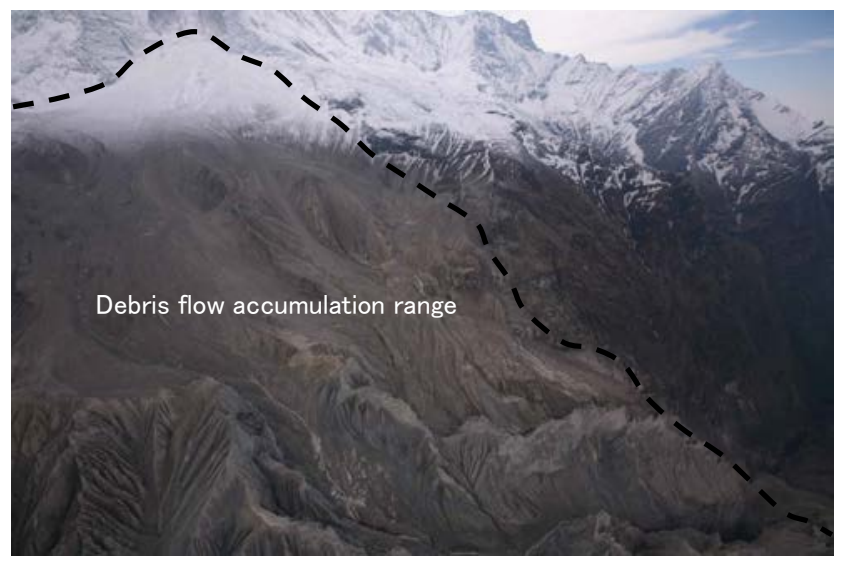

Fig. 6 Accumulation of debris flow at the foot of the gentle slope on the western wall of Annapurna peak IV (dotted line indicates the boundary of debris flow accumulation; taken at 08:10, June 4, 2012)

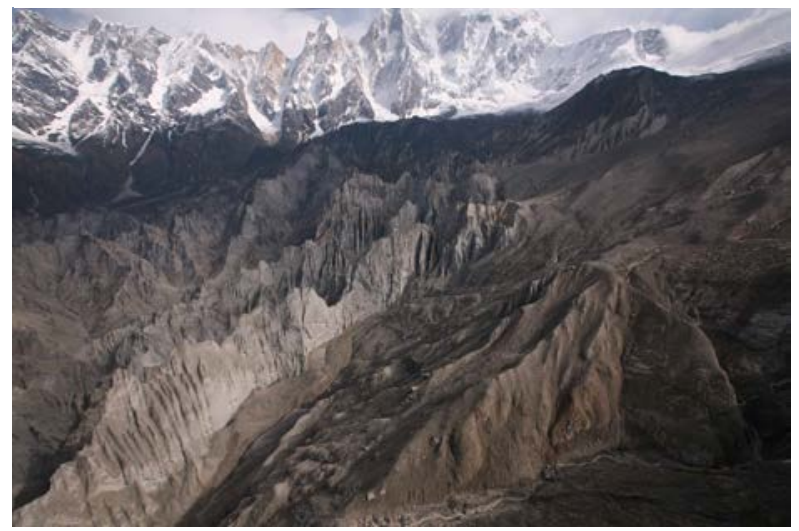

Fig. 7 Lacustrine sediments forming earth pillars (the pillar on the right of the photograph is rounded at the top)

highly likely that a portion of the debris flow had become mudflow at this point by incorporating snow and glacial material (Fig. 9).

In addition, coniferous trees grow in colonies on the upper slopes of the Seti Gorge, and some of them had collapsed in the flow direction or had dust 


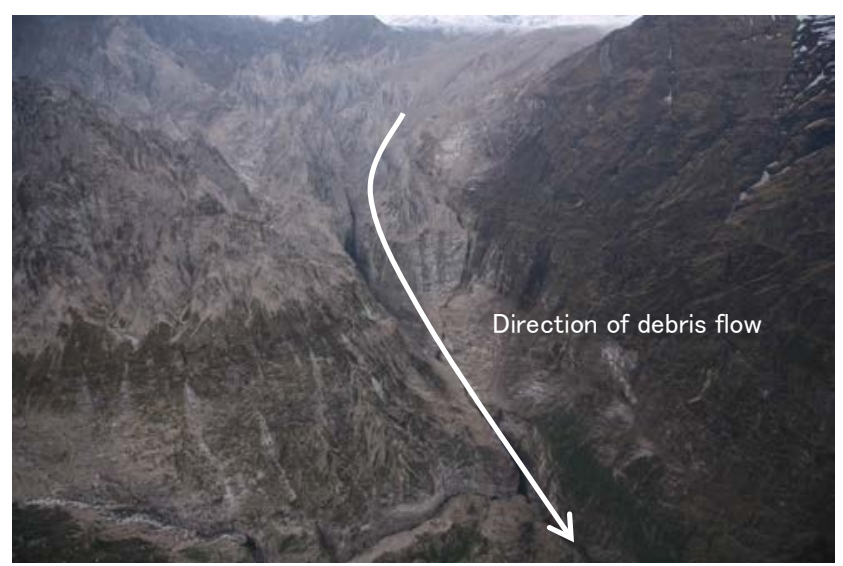

Fig. 8 Seti Gorge formed on limestone stratum (taken at 08:20, June 4, 2012)

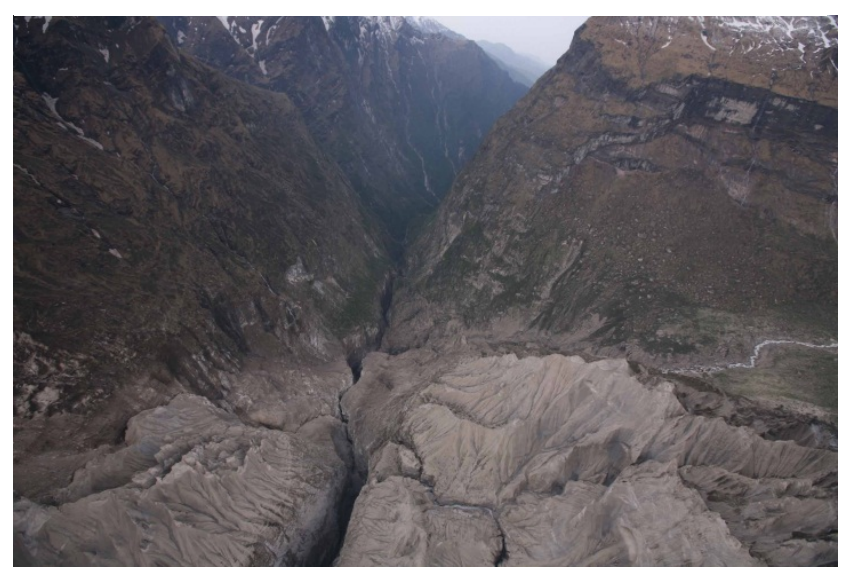

Fig. 9 Formation of Seti Gorge (adherence of mud from debris flow is seen at the bottom of the photograph)

from the debris flow adhering to their surface. (Fig. 10).

The International Centre for Integrated Mountain Development (ICIMOD), a local research institute, indicated that the river channel was clogged by a natural dam caused by a rockslide on the right bank immediately below the Seti Gorge. Initially, it was thought that the breaching of the natural dam was the cause of the flood. However, the probability of formation and collapse of a natural dam in the river channel seems low, as no signs of a natural dam were seen by helicopter aerial investigation and the topographic conditions indicate that only a small reservoir area could be formed at the site even if a natural dam was present.

\subsection{Conditions of the mudflow event}

The debris flow reaching the Seti Gorge (elevation $\sim 3,000 \mathrm{~m}$ ) is assumed to have developed into a mudflow by incorporating the former glacial deposits and river water. It is possible that the debris from the rockslide on the western wall of Annapurna peak IV had turned partly into a mudflow by taking in ice water as it flowed over the

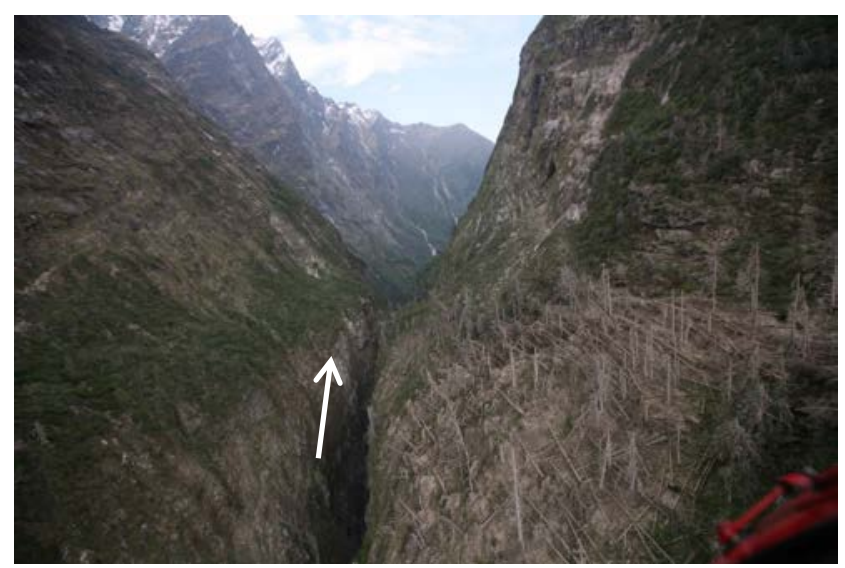

Fig. 10 Trees collapsing in the downstream direction (adherence of mud to tree surfaces is seen)

accumulated snow and the surface of the glacier. Traces of flow from the riverbed to several tens of meters downstream from the point of rockslide are evident (Fig. 11), where ICIMOD indicated the possibility of natural dam formation and collapse. These traces suggest that breach of a natural dam did not cause the disaster. Therefore, a mudflow had occurred by this point. Also, the mudflow had the ability to advance. As seen in Figs. 12 and 13, traces of mudflow running over the bank of the elbow-shaped bend are evident.

The residential houses in the Sadal region that escaped damage were located in the settlement on the terrace at $\sim 20 \mathrm{~m}$ above the riverbed (front in Fig. 14). In Yomo village, downstream of the Sadal region (Fig. 15), 11 of 13 houses were washed away, and one person died. In Kapuche village, downstream of Yomo village, the river channel forms a narrow pass with considerable bending and a width that decreases rapidly from $\sim 200$ to $20 \mathrm{~m}$ (Fig. 16).

Fine materials less than $20 \mathrm{~cm}$ in diameter comprising gravel with mud predominate in the flood deposits on the lower terrace. Gneiss and round gravels were not observed frequently. The main sources of this sediment were Tetyis sediments and Marl. In addition, a large amount of wood logs, which formed a temporary blockage at narrow pass in Kapuche village (Fig. 16), originated from the thick riparian forests along the Seti River.

The mudflow reached a height of $35 \mathrm{~m}$ above the riverbed at the point at which the width of the river channel decreased in Kapuche village, and the level of the mudflow reaching this height was horizontal, suggesting water logging. The hearing involving the residents of Kapuche village that took place on June 4 and 5, 2012 indicated that the area was filled with water, as a lake, for approximately 5 min after the arrival of mudflow, which then flowed down all at once. Therefore, when the mudflow arrived the 


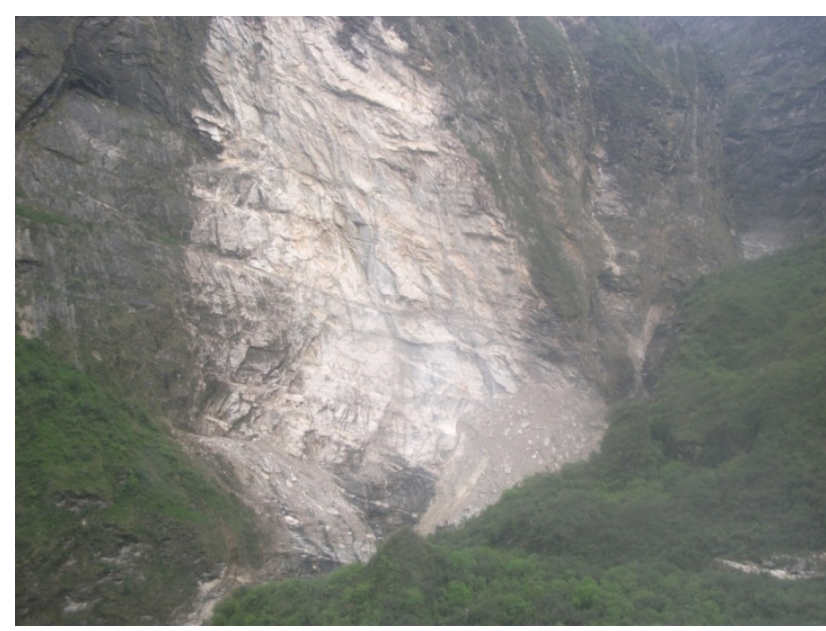

Fig. 11 Rockslide indicating the possibility of a natural dam (taken at 09:08, June 4, 2012)

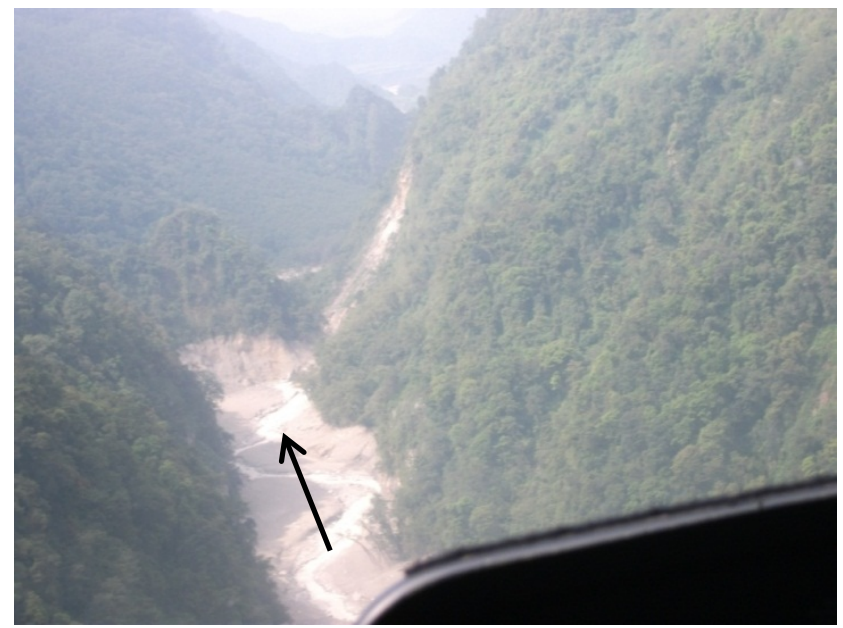

Fig. 12 Traces of mudflow at the elbow-shaped bend (taken at 09:10, June 4, 2012)

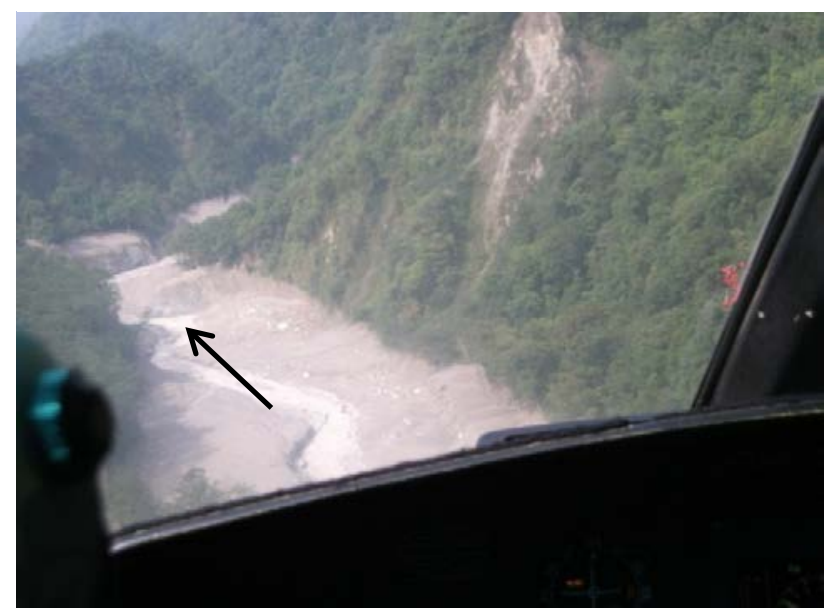

Fig. 13 Traces of mudflow at the elbow-shaped bend (taken at 09:12, June 4, 2012)

narrow pass was likely clogged, which was then breached, resulting in the material flowing farther downhill (Fig. 17).

The Kharpani region, in which there were many

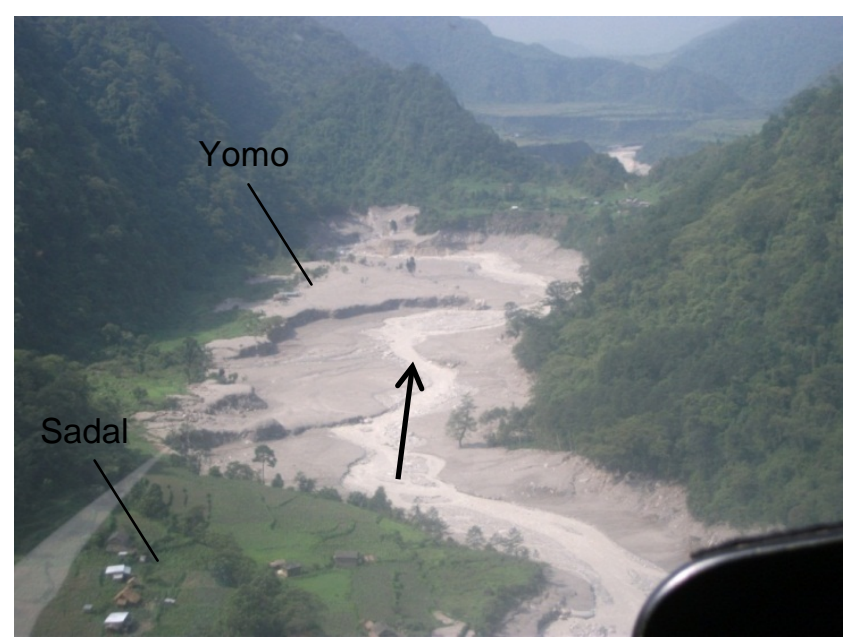

Fig. 14 Damage conditions from the Sadal region (bottom left) to Yomo village (taken at 09:15, June 4, 2012)

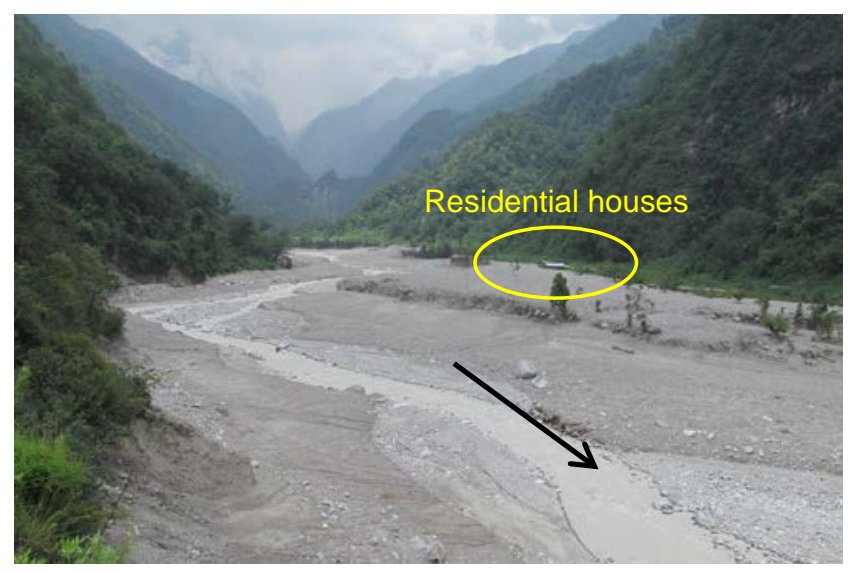

Fig. 15 Yomo village, where water logging occurred due to clogging at Kapuche village (residential houses that were not washed away can be seen at the center of the photograph)

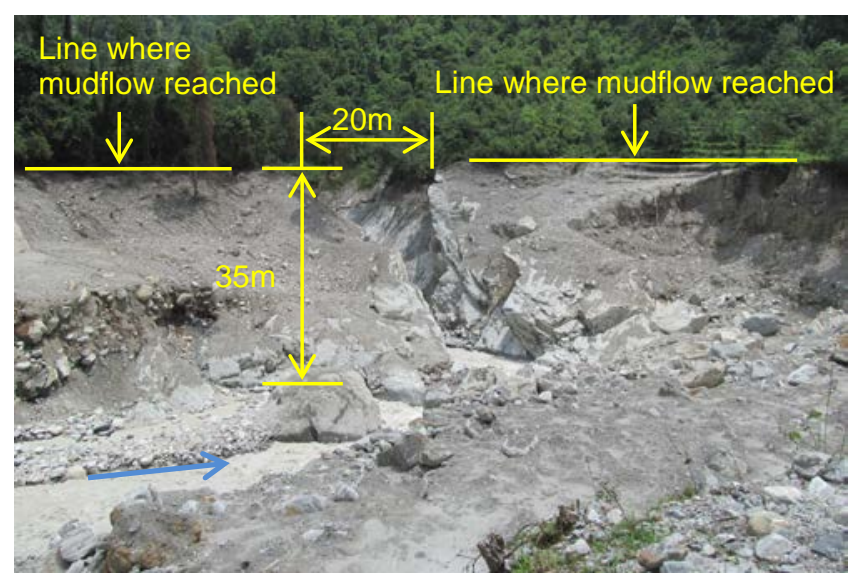

Fig. 16 Narrow pass in Kapuche village (collapsed after natural dam formation)

victims, is located $3 \mathrm{~km}$ downstream of the narrow pass in Kapuche village. It is assumed that the mudflow attacked the Kharpani region with increasing momentum due to the collapse of the natural dam (Fig. 18). In addition, the estimated speed of the mudflow, based on the distance travelled (260 m) and time elapsed (20 s) in a video 


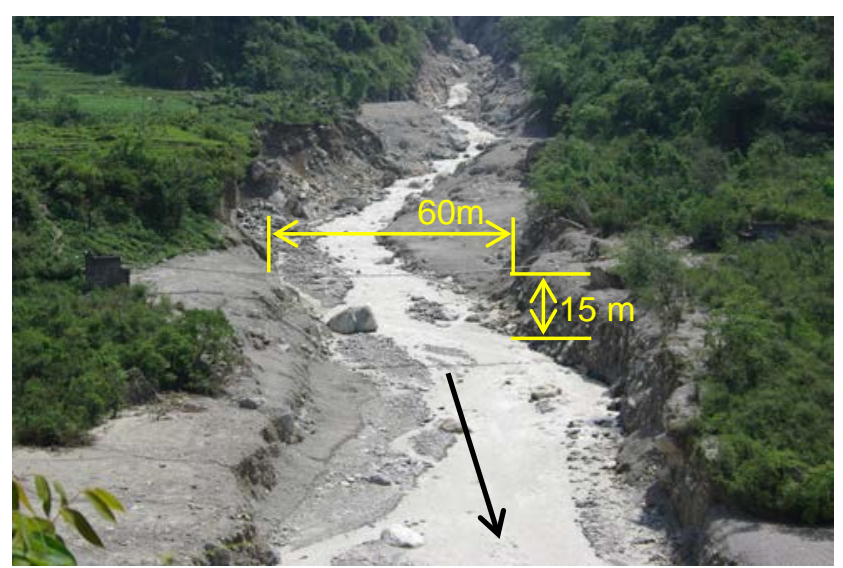

Fig. 17 River channel immediately below the narrow pass in Kapuche village

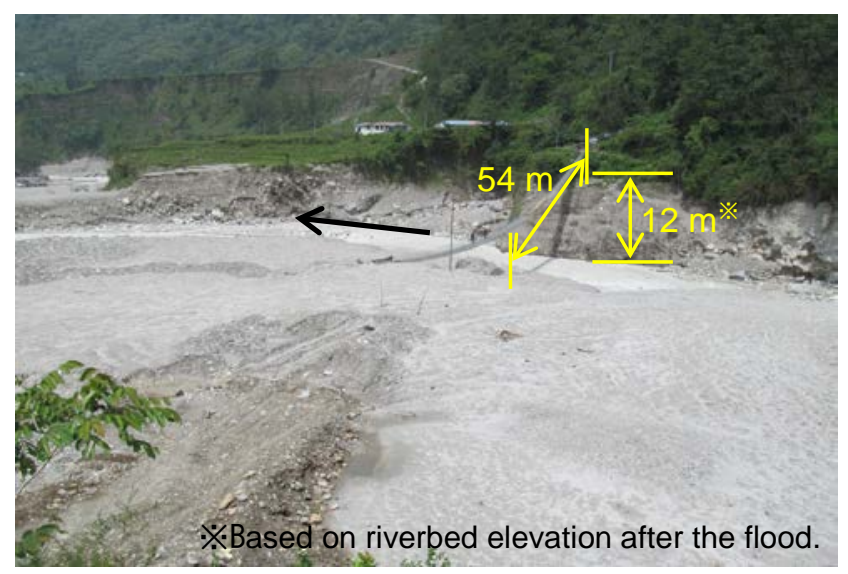

Fig. 18 Damage near the suspension bridge in the Kharpani region (suspension bridge at the center of the photograph caused clogging, and the flood water spilled over onto the surface of the terrace on the left)

image taken at the time of mudflow arrival, was $\sim 13.0 \mathrm{~m} / \mathrm{s}$. Meanwhile, as the traces of flow immediately downstream of the narrow pass (around the suspension bridge in Fig. 18) had a 60-m flow width and 15-m height, the peak flow volume at the location of the natural dam collapse was calculated to be $12,300 \mathrm{~m} 3 / \mathrm{s}$ using the Manning formula with a riverbed gradient of $5^{\circ}$. The roughness coefficient was assumed to be 0.1 , taking the debris avalanche block as the corresponding block. Based on the hearing that took place in the Kharpani region, temporary clogging occurred due to driftwood being caught at the suspension bridge, which is $12 \mathrm{~m}$ above the riverbed. A part of the mudflow changed direction toward the terrace at this point and washed away the residential houses etc. Most of the sediment that accumulated on the riverbed was fine-particle clay, as well as rubble with a diameter of $\leq 20 \mathrm{~cm}$ (Fig. 19). This fine particle sediment is thought to originate from Tethys sedimentary rock and glacial deposits from the upstream region of the Seti River.

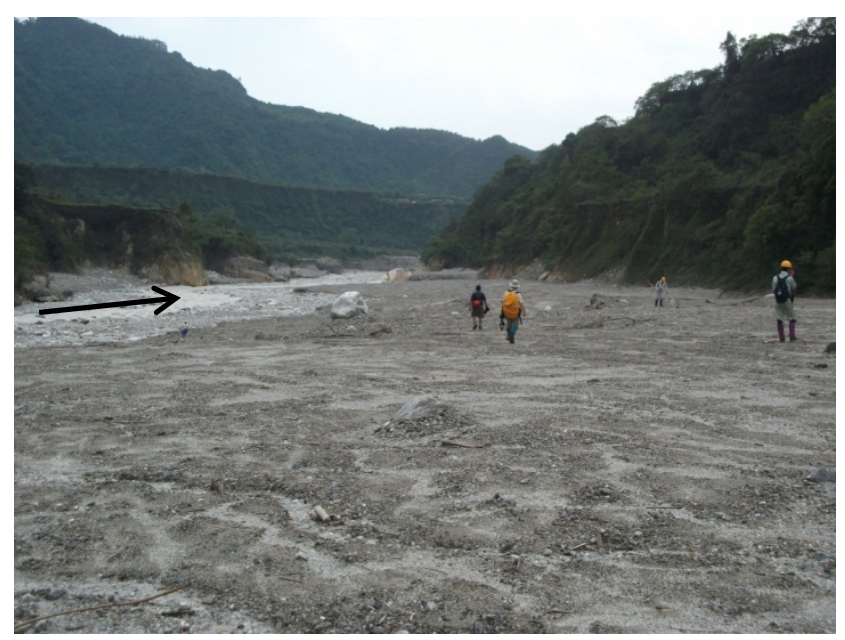

Fig. 19 Sediment comprising small rubble and fine-particle content (clay; taken at 14:10, June 5, 2012)

\section{SUMMARY}

Based on the results of this study, the characteristics of the rockslide and large-scale flood that occurred on May 5, 2012 along the Seti River can be summarized as follows:

1. The rockslide that occurred on the western wall of Annapurna peak IV formed a debris flow, which ran downhill while incorporating accumulated snow and glacial material and eroding the glacial deposit. This debris flow was assumed to have become in part mudflow.

2. The debris flow reaching the Seti Gorge became a mudflow as it integrated accumulated snow, meltwater from the glacier, and river water.

3. The mudflow became clogged at the narrow pass in the Kapuche region and then collapsed all at once, reaching the Kharpani region with increasing momentum.

4. The flow was clogged temporarily due to driftwood being caught by the suspension bridge in the Kharpani region. This changed the direction of the mudflow toward the terrace upon which restaurants for tourists were located (black frame in Fig. 1), resulting in a large number of victims.

Based on the results of the hearing, the direct cause of the rockslide could not have been an earthquake, heavy rain, or melting snow. The rockslide could have occurred as a large scale landslide, as the calcareous sedimentary rock forming the dip slope was exposed.

In addition, according to the witness information on dust in concurrence with the rockslide by a helicopter pilot, it is assumed that the rockslide occurred around 9:09 on May 5, 2012. As the mudflow arrived in the Kharpani region at 9:38, the flood travelled $30 \mathrm{~km}$ in only about $30 \mathrm{~min}$, an 
average speed of $16.7 \mathrm{~m} / \mathrm{s}$. This was likely because debris flow occurred after the rockslide and moved downhill at a high speed. A linear section with a steep gradient continued from the Seti Gorge downstream to Kharpani, even after changing into a mudflow.

\section{CONCLUSION}

This report summarizes the results of a helicopter investigation, field investigation, and hearing regarding the rockslide on the western wall of Annapurna peak IV and the resulting large-scale flood that occurred along the Seti River. In future, the information and data collected from the site should be analyzed, study the mechanisms of the flood event studies, and the possibility of similar phenomena on the Seti River and other rivers in the region examined. This study was conducted using a grant from the Kimura Fund of the Sabo Frontier Foundation. We hereby express our gratitude. On the final day of the investigation, a prompt report on this disaster investigation was presented at the official residence of the Japanese Embassy in Nepal which was attended by Ambassador Takahashi, Counselor Yanagihara, and First Secretary Hoshino from the embassy, Director Kawasaki and Assistant Director Fujii from the Japan International Cooperation Agency (JICA) Nepal Office, and people from the Nepali Ministry of Home Affairs, the Department of Water Induced Disaster Prevention, Tribhuvan University, the United Nations Development Programme (UNDP), the United Nations Office for the Coordination of Humanitarian Affairs (OCHA), the Nepal Risk Reduction Consortium, and the ICIMOD. Active discussion was held at the Japanese Embassy, and the necessity of establishing a simple alarm system for such sudden disasters was emphasized, along with elucidation of the underlying mechanisms. We hereby express our deep appreciation for the cooperation of all concerned parties in this study.

Lastly, we benefitted from the cooperation of even people who had lost their families or houses during the hearing; by such means were we able to obtain information on the conditions of the disaster. We sincerely hope that these people will be able to return to their normal life as soon as possible.

\section{REFERENCES}

Dahal R.K., Bhandary N.P and Okamura M., (2012): Why 1255 flash flood in the Seti River? - a brief report published in www.ranjan.net.np.

Received: 20 June, 2014

Accepted: 14 July, 2014 